\title{
The DC-link of the inverter system BUSSARD for ASDEX Upgrade in vessel saddle coils
}

\author{
Nils Arden ${ }^{\mathrm{a}}$, Horst Eixenberger ${ }^{\mathrm{a}}$, Michael Rott ${ }^{\mathrm{a}}$, Michael Schandrul ${ }^{\mathrm{a}}$, Wolfgang Suttrop ${ }^{\mathrm{a}}$, Markus \\ Teschke $^{\mathrm{a}}$ and the ASDEX Upgrade Team
}

${ }^{a}$ Max Planck Institute for Plasma Physics, Boltzmannstr. 2, 85748 Garching, Germany

For the nuclear fusion experiment ASDEX Upgrade (AUG) an inverter system to individually feed the 16 in-vessel saddle coils was built. After an operating phase with four inverters that supplied groups with up to 4 coils connected in series, now the full system is working. The common DC-link is feed by an existing current-mode thyristor rectifier.

This publication describes the modifications in order to stabilize the DC-link voltage under all load conditions.

Keywords: ASDEX Upgrade, current-mode thyristor rectifier / converter, DC-link supply, arc detection system, linearization

\section{Introduction}

A set of 16 in vessel saddle coils (dubbed "B-Coils") has been installed into ASDEX Upgrade (AUG). Initially, these coils have been operated at low bandwidth or direct current (DC) only. In order to use the B-coils up to their specified bandwidth of DC ... $500 \mathrm{~Hz}$ with alternating currents (AC) of arbitrary waveforms, a new inverter system with 16 individual power inverters was built. After an initial operating phase with 4 inverters, now the full system is working $[1,2,4]$. The inverter system has a common DC-link which is fed by 2 thyristor rectifiers operated in voltagecontrol mode.

\section{DC-link supply}

\subsection{Group 0 - current-mode thyristor rectifier}

The current-mode thyristor rectifier Group 0 is a 15 years old system, which was mainly used for the supply of test bench coils. It consists of two independent 2quadrant thyristor rectifiers (modules 0.1 and 0.2). Each module can provide a current of up to $4 \mathrm{kA}$ at a voltage of $340 \mathrm{~V}$ or $600 \mathrm{~V}$ (star- or delta-circuit configuration) for 10 seconds.

Each module is controlled individually. The control system is realized with the digital Logidyn-D2-system, offered by Alstom. It is set up by means of a graphical programming software, called Logicad. Some software parts (like the current control), which require a short cycle time, are implemented in machine language and can only be modified by the supplier with a special compiler. Unfortunately, support of this system has ceased and so only limited modifications can be performed.

For the supply of test bench coils the thyristor rectifier is operated in current control mode, only. For BUSSARD application voltage control mode is required.
Therefore the control concept of the thyristor rectifier had to be adjusted for the new application, while currentmode coil power supply still needs to be possible for other test benches. With these boundary conditions, the new control concept has been designed and tested.

\subsection{Optimized output inductance}

For the new application the output inductance of the thyristor rectifier had to be adjusted. The existing output inductors had a value of $1.75 \mathrm{mH}$. However, there is a possibility to short-circuit them by disconnectors. So it is possible to keep the old chokes for other applications and only short-circuit them for operation of BUSSARD.

The task of the new output chokes is to limit the capacitive charge current. On the other hand every serial inductance costs dynamic (di/dt) and reduces voltage stability. Therefore, the inductance has to be chosen carefully.

Simulations showed that a value of $0.1 \mathrm{mH}$ seems to be a good compromise. Also the resistance of the inductors should be as small as possible to limit voltage losses.

In the operation phase it shows only small voltage drops and overshooting. The resonance frequency of output inductance and DC link capacity that is about 63 $\mathrm{Hz}$ is not excited by the switching frequency of the inverters. This means that the inverters are sufficiently decoupled from each other and the DC link for all relevant operation scenarios [4].

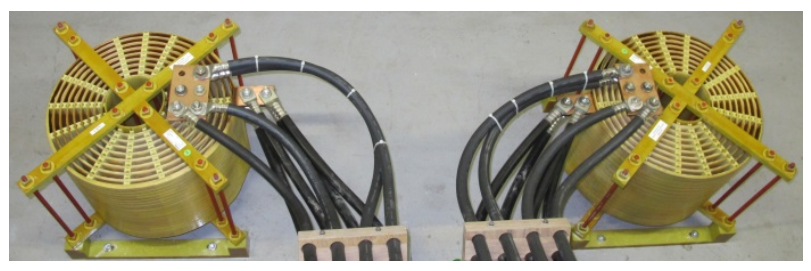

Fig. 1: New output inductors (air-core coils, 2x $100 \mu \mathrm{H}$, 1500A @ continuous operation, 525x525x510 mm (LxWxH) ) 


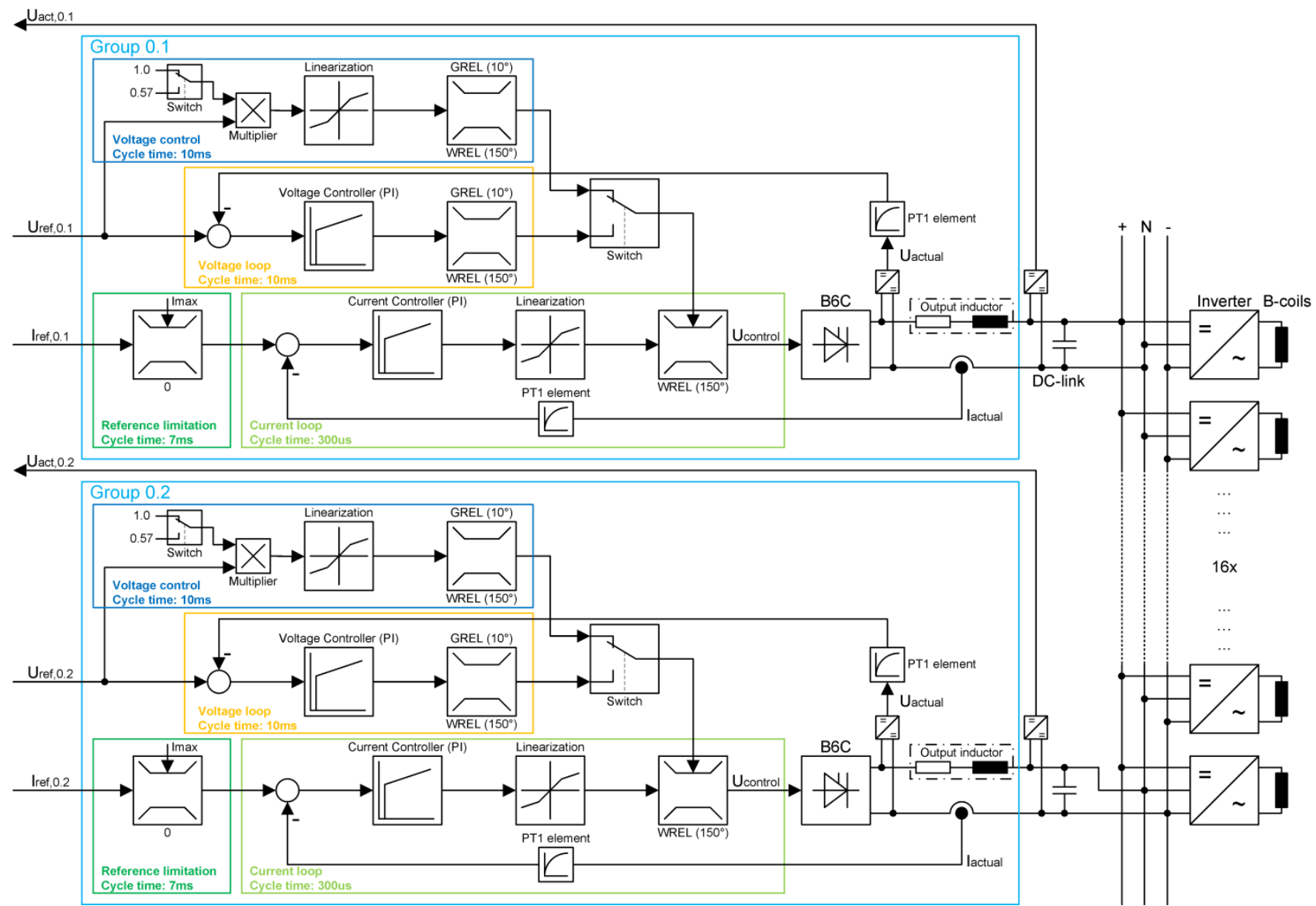

Fig. 2: Control schematic of Group 0

\subsection{Open-loop voltage control}

Many tests with a closed-loop control were done, but showed problems by mutual interference with the internal control-loops of the inverters at low voltage (see also [4]). Another problem of closed-loop control is that Group 0 is a 2-quadrant converter and so only control errors in one direction can be compensated.

The "voltage loop" (yellow box) shown in figure 2 was already integrated in the control system by the supplier and is only used as a voltage limitation for the current-mode control. Thus the implementation is not perfect and has no linearization, because of the low needs for the use as a limitation. For the new application it is not suitable.

In order to avoid these problems, finally open-loop control has been chosen. To use this control-concept the programming of the control system has been changed and the part "voltage control" (blue box) and the switch to change between the "voltage control"- and the "voltage loop"-part in figure 2 has been added. The "current loop" (green box) is used as a current limitation for the new application.

To determine the characteristic of the control system, tests without linearization were done. The result is shown in figure 3 (blue line). The non-linear relationship between the firing angle and the output voltage is clearly visible. The theoretical dependence is

$$
U_{\text {actual }}=U_{\max } \cdot \cos \alpha \text { with } \alpha=0 \ldots \pi
$$

The firing angle $\alpha$ is synonymous with the control voltage $\mathrm{U}_{\text {control }}$ of the control system $\left(\alpha=0 \ldots \pi\left(0 \ldots 180^{\circ}\right) \triangleq U_{\text {control }}=0 \ldots 1\right)$.

To avoid problems, like commutation failure, the firing angle is limited between $10^{\circ}$ and $150^{\circ}$.

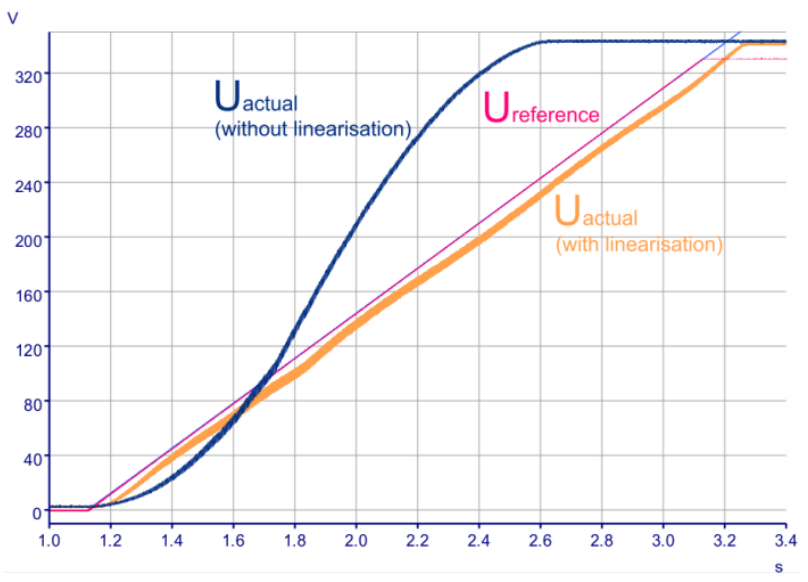

Fig. 3: Open loop control without and with linearization 
To eliminate further deviations, because of signal propagation times or inaccurate amplification factors, the theoretical equation was not used for the linearization.

But with the experimental results a polynomial interpolation (figure 4) for the linearization could be fitted. A polynomial of $7^{\text {th }}$ order shows good agreement with the measured data:

$$
\begin{gathered}
Y=0.129+4.492 x-47.444 x^{2}+335.141 x^{3} \\
-1363.385 x^{4}+3116,156 x^{5}-3702.402 x^{6}+1779.139 x^{7}
\end{gathered}
$$

Final tests after the integration of the linearization polynomial showed that $\mathrm{U}_{\text {actual }}$ tracks $\mathrm{U}_{\text {reference }}$ well (figure 3 / orange line vs. red line).

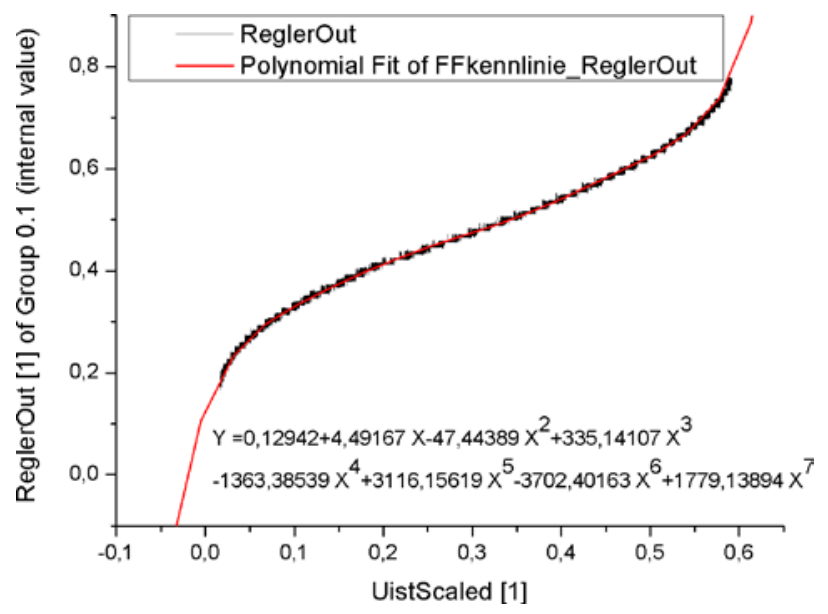

Fig. 4: Linearization curve and equation

The here shown results are for the rectifier module 0.1 . Due to inaccuracies within the analog circuits, the results for module 0.2 differ to module 0.1 and so an adjusted polynomial was calculated. Because of these individual polynomials, the signals $\mathrm{U}_{\text {control(0.1) }}$ and $\mathrm{U}_{\text {control(0.2) }}$ in figure 5 show different trends.

\subsection{Experimental results}

At the end of the last AUG campaign 16 BUSSARD inverters were used for the first time.

The results for the DC-link are shown in figure 5. The DC-link of BUSSARD is charged synchronously with the ramp-up of the toroidal field of ASDEX Upgrade. Due to leakage currents of the thyristors and snubber circuits the open-circuit voltage rises always at least to $U_{\max } / 2$, even for thyristor firing angle $\geq \pi / 2$.

During the whole AUG-shot the DC link voltages showed a good stability (no oscillations or deep voltage drops). The overvoltage before and after load phases has to be accepted, because the firing angle needed for operation with load differs from the firing angle for freewheel operation (no closed-loop controlling, anymore!).

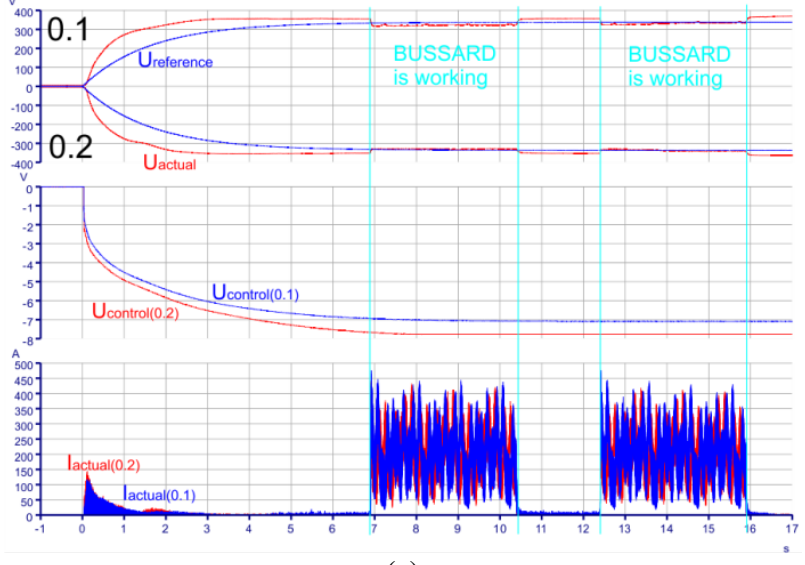

(a)

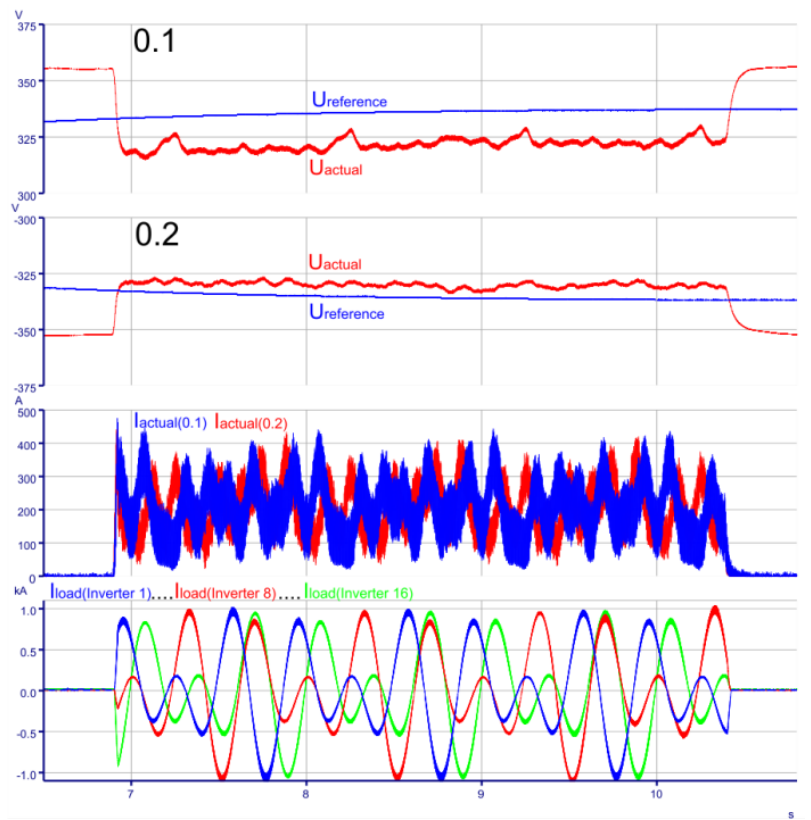

(b)

Fig. 5: Measurements of DC-link and Group 0 during AUG-shot \#33723 (16 inverter in phase-shifted operation with currents of up to $1.1 \mathrm{kA}$ and a frequency of $2.5 \mathrm{~Hz}$ )

(a) complete AUG-shot

(b) zoom of one BUSSARD operation period

\section{Safety systems}

For the personal and plant safety of BUSSARD and especially its DC-link numerous safety functions have been integrated. There is an emergency circuit, which can be triggered by several emergency push buttons, door contact switches, the electronics of the inverters, the control system of Group 0, the arc detection system and the safety system of ASDEX Upgrade [3].

A triggering of the emergency circuit will open the circuit breaker of Group 0 and fast discharge the DClink.

The operation mode (grounded / no voltage / operation) of BUSSARD and its DC-link is always visible by signal lights. 
The discharge unit is realized with a DC power contactor with normally closed main contacts to be safe even if a cable break is occurring or by an outage of the auxiliary voltage. Two dump resistors of $7.5 \Omega$ discharge the positive and negative DC-link within $2.4 \mathrm{~s}$ (time constant is $480 \mathrm{~ms}$ ).

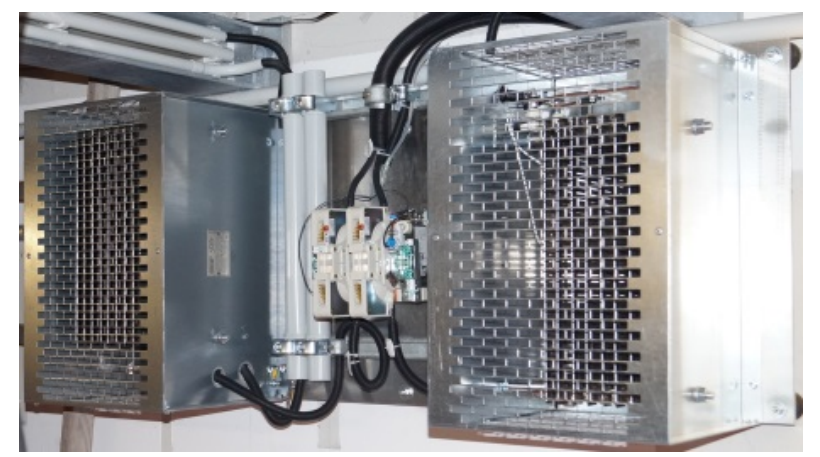

Fig. 6: Discharge unit (2 dump resistors and DC power contactor with normally closed main contacts)

To protect BUSSARD against arcs an arc detection system was integrated. After a brief market survey a decision was made to use the commercial system PGR8800 from Littelfuse. This was the system with the best match to our needs, which are:

- short reaction time

- simple integration

- self configurable

- costs

The system consists of four controllers with up to 6 sensors each. The controllers can be interconnected by a bus-system. There are two types of sensors: point sensors and fiber optic line sensors. Every inverter cabinet has a point sensor, which monitors the inverter modules and the internal wiring. The fiber optic line sensors are mounted below the busbars to monitor the DC-link. If an arc is detected the system reacts within $1 \mathrm{~ms}$ and triggers the emergency circuit.

To deflect the shock pressure during an arc, deflecting blades were mounted below the cabinets. By this, the shock pressure is deflected into a closed technical room where no human can be injured.

\section{Summary and Outlook}

The new system with 16 inverters has been commissioned successfully. The thyristor rectifier Group 0 was enhanced for this new task. The control system has been adapted for this purpose and new output inductances were designed and integrated.

Also, safety systems for a safe operation of the DClink were created and tested.

For best performance of BUSSARD it is planned to account for the behavior of the DC-link in the control algorithm of the 16 inverters. This has been prepared but not yet tested [4].

\section{Acknowledgments}

This work has been carried out within the framework of the EUROfusion Consortium and has received funding from the Euratom research and training programme 2014-2018 under grant agreement No 633053. The views and opinions expressed herein do not necessarily reflect those of the European Commission.

\section{References}

[1] M. Teschke et al, Power inverter design for ASDEX Upgrade saddle coils, Fusion Engineering and Design 88 (2103) 1469-1474

[2] M. Teschke et al, Electrical design of the inverter system BUSSARD for ASDEX Upgrade saddle coils, Fusion Engineering and Design 96-97 (2015) 171-176

[3] M. Rott et al, Electrical and mechanical adaptation of commercially available power inverter modules for BUSSARD - the power supply of ASDEX Upgrade in vessel saddle coils, Fusion Engineering and Design 98-99 (2015) 1144-1147

[4] M. Teschke et al, Optimizing BUSSARD, the new 16phase inverter system of ASDEX Upgrade, Fusion Engineering and Design, this conference 